\title{
Ionized Air as a Process Medium for Machining
}

Karol Vasilko. Rudolf Matija

Faculty of Manufacturing Technologies, Technical University of Košice, 08001 Prešov, Bayerova 1., SR, M: karol.vasilko@tuke.sk, rudolf.matija@tuke.sk.

The application of cutting liquids in the machining of the pertsgreatly affects the working environment. Descpite the efforts to prolong life, chemical aliminaion of bacteria formation, development of new liquid configurations, their negative influence on production (health hazard to the operator, corrosion of workpieces, need of recycling or disposal), it outweighs the benefits (decrease of cutting forces, cutting temperature reduction). The good is a gaseous environment. The current gaseous environments show the current application of ionized air. In the article are experimental results when applying this media during machining.

Keywords: machining, lubricants, cooling, ionozed air

\section{Design of the application of zone cooling by ionized air}

Applied gasiform cutting environment has similar effects to the fluid one. In the reaction with machined surface and the surface of cutting material, coatings are created which influence tool durability and the quality of machined surface depending on the sort of environment [3].

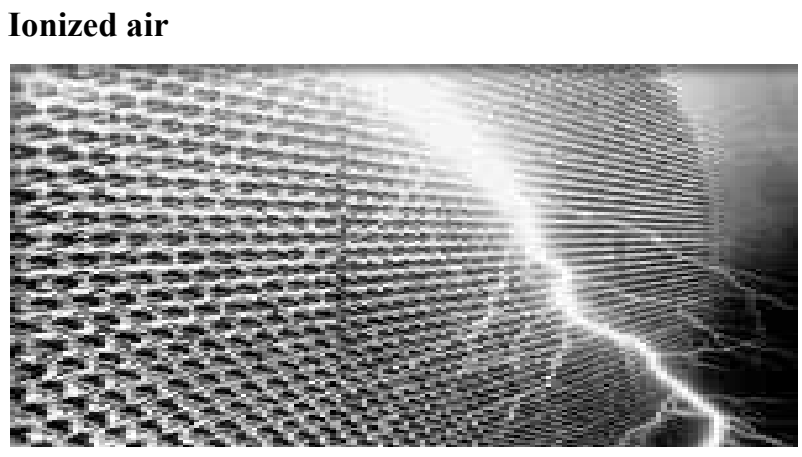

Fig. 1 The course of the corona discharge on the center emitters

In regular conditions, the molecules of air behave neutrally with no free electones present. Due to this fact, air does not conduct electricity. Air conductibility begins with ionization and is based on the fact that by the influence of outer forces, an electrone is released from a neutral molecule and the rest of the molecule behaves like a positively charged element, a positively charged ion. When connected with another molecule, the released electrone changes into a negatively charged ion. Connecting with the positive ion, a neutral air molecule is created back. Besides these light ions, air also contains heavy ions created by a cluster of molecules and charged elements of dust, smoke, water drops, etc. Ionization of gasiform medium requires certain ionization energy.

Recently, three air ionization methods are used in different measures. The simplest one, but from the safety viewpoint least frequently used method, is the use of radioactive alfa emitter. A more spread one, but not entirely without problems, is the use of so-called Lenard effect, i.e. water jet splitting. These hydrodynamic ionizators are more frequently used in therapeutic version. For this type, the problem is presented by how to maintain water sterile as well as excessive environment humidification, which can destroy the original positive effect. The most widely spread method of ionization, mainly for home-use ionizators, is electric method. However, not by spark discharge like in nature, but a silent corona discharge on cusped emitters. This method also brings about certain risks. Some simpler devices, mainly with metal emitters, are a source of ozone and nitrogen oxide (very toxic gases).

Carbon fibres, which posses thousands of unwornable spikes on their surfaces can be considered to be the best emitters.

\section{Ozone}

A three-atom oxygene molecule was discovered in 1785. In 1840 this gas was named after a Greek word „ozein“ - emit fragrance - OZONE. The construction of the first ozone generators and their use on bacteriological germs, animal and human mucosa dates back to 1857 . In June 1896 Nicola Tesla patented his first ozone generator and in 1900 he founded his Tesla Ozone Factory.

\subsection{Physical characteristic}

Ozone is an active form of oxygene, it is a three-atom molecule $\mathrm{O}_{3}$, its molecular weight is $48\left(\mathrm{O}_{2}\right.$ molecule has molecular weight is 32 ). In regular conditions, ozone is a gas which is well dissolvable in water. It boils at $111.9^{\circ} \mathrm{C}$, hardens at $-192.5^{\circ} \mathrm{C}$, in gas state its color is light blue and in liquid state its color is dark blue to redpurple.

The molecule is created by a isosceles triangle with the angle $127^{\circ}$. It reaches maximum of ultraviolet light at wavelength $\lambda=253.7 \mathrm{~nm}$. In lab conditions, ozone is normally made by the influence of silent electric discharge on oxygene, by this $10 \%$ concentration can be obtained. Pure ozone can be obtained by fraction liquefaction of the mixture $\mathrm{O}_{2}-\mathrm{O}_{3}$. It is a two-phase system of liquids: one contains $25 \%$ ozone, it is non-variable, the second phase, dark-red one, contains $70 \%$ ozone. It is explosive, the same as pure liquid ozone. A little amount of ozone is created at electrolysis of diluted sulphuric acid, some chemical reactions producing elementary oxygene and influence of ultraviolet light on $\mathrm{O}_{2}$. Ozone dilutes in water approximately ten times more than oxygen. 


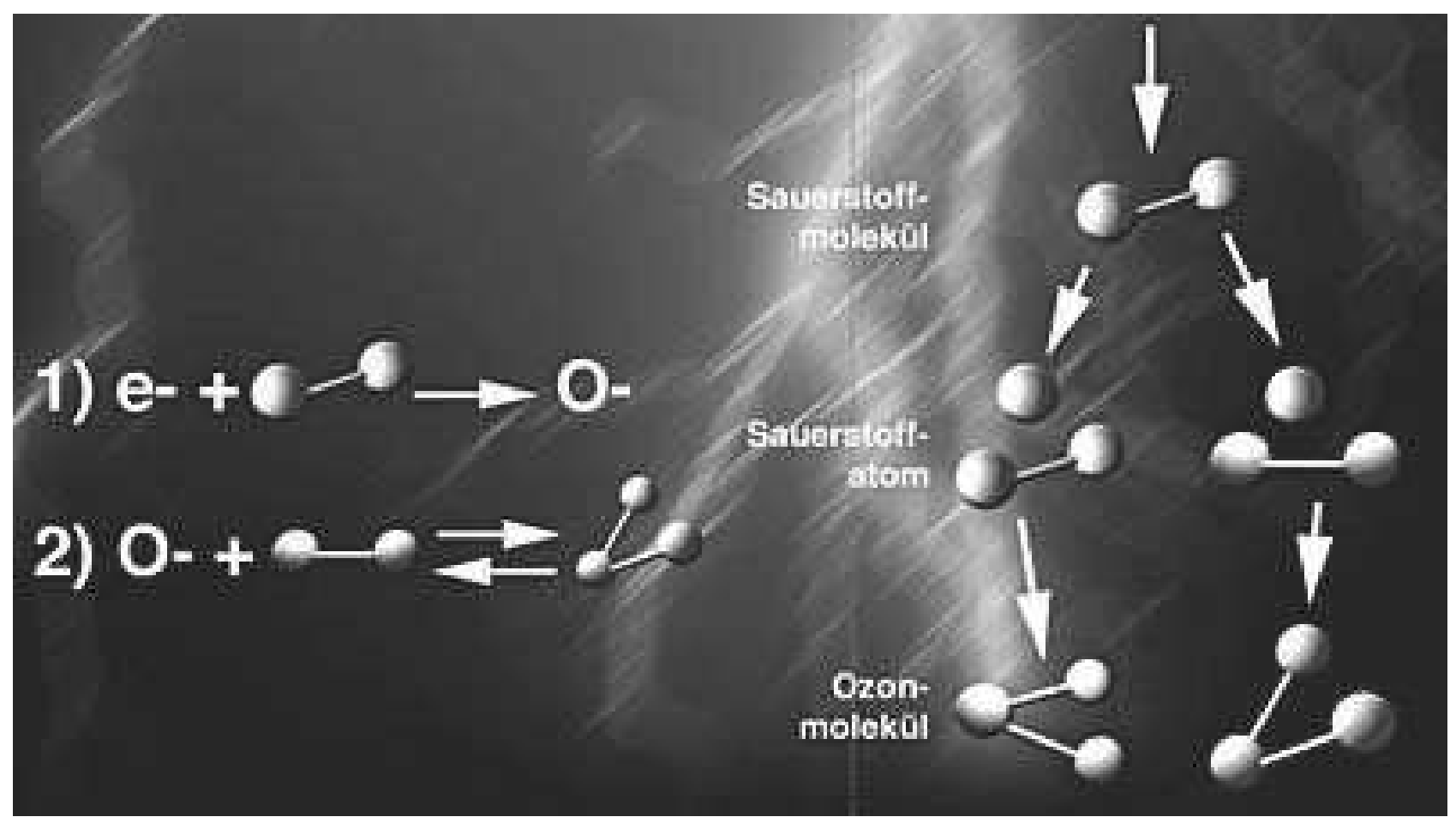

Fig. 2 Ozone creation cycle

\subsection{Chemical characteristic}

Ozone is the strongest known oxidative agent and reacts with many substances in conditions where $\mathrm{O}_{2}$ does not react. However, a part of $\mathrm{O}_{3}$ dissolves before it can react with dissolved substances.

Ozone desintegration is a catalytic reaction, it is done quicker in alcalic environment. Ozone effectively oxidizes cyanides and detoxicates them by this.

Ozone can be used for accelerated tests of material resistance against oxidation and photochemical influences. It effectively shaves off polymere substances of synthetic and natural origin. Ultraviolet radiation speeds up and strenghtens its oxidation and decomposition qualities.

Ozone decomposition in water depends on temperature, $\mathrm{pH}$ and water quality. Hal-time of disintegration is $10 \mathrm{~min}$. Chlorides and bromides in water solutions are oxidized by ozone to hypochlorites, iodides to elementary iodine, ammonia to nitrates, cyanides to quanatanes. By the oxidation of organic compound by ozone, mostly carbon acids and sulphic acids are formed. Amines and aminoacids are oxidized by ozone slowly.

Ozone $\left(\mathrm{O}_{3}\right)$ is one of the strongest oxidation agents. In troposphere it is created indirectly by the effect of sunshine into nitrogen oxides in the presence of evaporable organic substances. There does not exist any essential direct anthropogenic ozone emissions into air. Ozone present in the atmosphere is created by chemical reactions which occur in the air. The processes producing and using ozone which contain the absorption of sunshine by nitrogen oxide can be characterised by the following reactions:

$\mathrm{NO}_{2}+h \mathrm{n}>\mathrm{NO}+\mathrm{O}^{*}$

$\mathrm{O}^{*}+\mathrm{O}_{2}>\mathrm{O}_{3}$

$\mathrm{O}_{3}+\mathrm{NO}>\mathrm{NO}_{2}+\mathrm{O}_{2}$

In stabilised state, the ozone concentration can be described by the formula:

$\mathrm{O}_{3}$ concentration $=$ constant $\times\left(\mathrm{NO}_{2}\right.$ concentration)/(NO concentration)

The presence of hydroxyle radicals and evaporable organic compounds in the air, of natural or anthropogenic origin, causes the shift of the balance of much higher concentrations of ozone. Other oxidants, e.g. peroxyacylnitrates, nitric acid, hydrogen peroxide, secondary aldehydes, formic acid, and whole spectrum of radicals with short-term existence are created by photochemical processes besides ozone. Maximum ozone concentration, which can be obtained in polluted air, probably depends not only on absolute concentrations of evaporative organic compounds and nitrogen oxides, but also their ratio. At mean values of these ratios of concentrations (4:1 to $10: 1$ ), the conditions for the formation of high ozone concentrations are positive.

\subsection{Use}

Ozone is the strongest oxidation means which is available to people. Technical use of ozone exists in many applications. Together with its vast oxidation abilities, ozone shaves off high-molecular compounds and disrupts poisonous aromatic substances. When rayed by UV rays, the destruction of chlorinated biphenyls, including the following DDT products, is enabled. Recently is has been found out that ozone is more effective in the destruction of various viruses than chlorine. Ozone antiseptic features are applied in conditioning of drinking water, which has been used in a number of urban conglomerations for nineteen years.

Its another technical use is as a bleaching material in textile industry, at iron and manganese production, bottling of mineral water, food industry and photochemistry. Technically utilizable ozone features can be listed as 
follows: smell reduction, taste reduction, organic compounds oxidation, detergents elimination, cyanides oxidation, $\mathrm{Mn}$ and Fe oxidation, sulphur elimination, viruses/bacteria/funghi elimination or inactivation.

\subsection{Presence}

Ozone is the element which is commonly present in nature - twenty to thirty kilometers above the ground level, where it is created by the effect of UV spectrum of sunshine from athmospheric oxygen, i.e. influence of energy, from three $\mathrm{O}_{2}$ molecules, two $\mathrm{O}_{3}$ molecules are formed. Through this reaction ozone layer - ionosphere is formed, which provides protection against UVC and UVB rays.

It is formed through the following reaction:

$3 \mathrm{O}_{2}+$ energy $=2 \mathrm{O}+2 \mathrm{O}_{2}=2 \mathrm{O}_{3}+$ energy

The same process goes on at the production of ozone in generators

When 2 molecules $\mathrm{O}_{3}$ meet, 3 molecules $\mathrm{O}_{2}$ are formed and energy is released

$\mathrm{O}_{3}+\mathrm{O}_{3}=3 \mathrm{O}_{2}+286 \mathrm{~kJ}$

The same process continues when the ozone dilluted in liquid is disintegrated.

Ozone layer is disrupted mainly by fluorocarbonated hydrocarbons used in cooling devices, air conditioning devices, in the production of dissolvents and foam artificial synthetics. There also occurs increased incidence of space rays on Earth surface and changes of weather. Damages of cornea of animals and humans can also occur.

Ozone is a gas with characteristic smell, or aroma, which we can smell in the air after a typical summer storm or the use of sun lamp but also a copy machine. Humans are especially sensitive in smelling those and they are able to feel also harmless concentration of it in the air. Ozone is also created by the change of oxides and dioxides of nitrogen from exhaust gases. So-called photochemical smog is created as a result of UV radiation, the part of which is also ground ozone. This can easily be detected photometrically so it serves as a measure of air pollution. So ozone is the outcome, not the result of pollution.

\subsection{Oxidation}

Because on its surface, metals encounter different environments it is necessary to study their features on phase border, on which typical oxidation in the presence of oxygene for metals.

Air is inhomogenous gaseous matter based on compounds of different gases, anorganic substances, bacteria, water vapour, etc. From chemical viewpoint it mainly consists of gaseous elements of nitrogen and oxygen, besides which also precious elements from argone group as well as traces of ozone can be found. Besides nitrogen, which is chemically inactive, i.e. little conformable; oxygen is the most important element of the air. When metal surface comes in contact with gaseous oxidation atmosphere, a film of reaction product is created, grows in different ways, or falls off if the layer is thick.

Oxidation is a phenomenon during which the reacting substance, in our case metal with valence $n$, loses valence electrones. Reaction of gaseous oxygen with metal is not the only phenomenon considered to be oxidation, but also the influence of sulphur vapors and halogens in gaseous or liquid states.

During metal oxidation in which different compounds with different valence are created, as it happens e.g. for iron oxides, and the decisive element is free enthalpy of compound formation and decides which reaction is possible, i.e. mainly outer conditions (temperature, pressure) decide about which oxide is formed.

The following influences the speed and growth of oxidation layer:

- Reaction kinetics on phase borders (at least two phase borders exist at the formation of oxidation layer)

- metal - layer,

○ layer - atmosphere

- Elementary elements diffusion by the formed layer

The phenomenon which is the slowest, which the most frequently is the diffusion by the layer, decides about the resulting speed of layer growth.

At certain metal capacity $v_{\mathrm{k}}$, we can find out the value of the layer $v_{\mathrm{o}}$, which was formed by the oxidation of this amount of metal. The reacting mass is $v_{\mathrm{k}} \delta_{\mathrm{k}}$, where $\delta_{\mathrm{k}}$ is the metal specific weight. From this, $\left(M_{\mathrm{o}} / M_{\mathrm{k}}\right) v_{\mathrm{k}} \delta_{\mathrm{k}}$ of reaction product is formed, the volume of which is:

$$
v_{\mathrm{o}}=\left(M_{\mathrm{o}} / \mathrm{M}_{\mathrm{k}}\right) \cdot\left(v_{\mathrm{k}} \delta_{\mathrm{k}} / \delta_{\mathrm{o}}\right)
$$

where

$M_{\mathrm{o}}$ - molecule weight of resulting compound, $\delta_{\mathrm{o}}-$ specific weight of resulting compound

$M_{\mathrm{k}}$ - molecule weight of reacting metal

If $v_{\mathrm{o}}<v_{\mathrm{k}} \mathrm{t} . \mathrm{j} . \frac{v_{0}}{v_{k}}<1, \quad$ the layer does not cover metal completely and is not sufficiently protected from the effect of reacting gas. However, if $v_{\mathrm{o}} \geq v_{\mathrm{k}} \mathrm{t}$.j. $\frac{v_{0}}{v_{k}} \geq 1$, the layer covers metal completely and it depends on its features, to which extent is the growth of the layer slowed down depending on time.

This simple rule was claimed by Pilling and Bedworth in 1923. It presents volume ratio $\frac{v_{0}}{v_{k}}$ in reaction of some metals with dry oxygen. Pilling - Bedworth rule can also explain the behavior of other layers than the oxide ones.

Tab. 1 Volume ratio in reaction of some metals with dry oxygen

\begin{tabular}{|c|c|c||}
\hline metal & oxide & $v_{0} / \mathrm{v}_{\mathrm{k}}$ \\
\hline $\mathrm{Al}$ & $\mathrm{Al}_{2} \mathrm{O}_{3}$ & 1.28 \\
\hline $\mathrm{Zn}$ & $\mathrm{ZnO}$ & 1.44 \\
\hline $\mathrm{Cu}$ & $\mathrm{Cu}_{2} \mathrm{O}$ & 1.71 \\
\hline $\mathrm{Fe}$ & $\mathrm{FeO}$ & 1.80 \\
\hline $\mathrm{Fe}$ & $\mathrm{Fe}_{3} \mathrm{O}_{4}$ & 2.12 \\
\hline $\mathrm{Ni}$ & $\mathrm{NiO}$ & 1.64 \\
\hline
\end{tabular}




\section{Definition of problem}

Recent development in the area of production technology has great influence on the progress of cutting conditions for machining surface [1],[2],[7]. Recently, the application of the progressive gaseous process media has growing tendency thanks to the decrease of total costs and improvment of the working and life environment.

The requirements on lubrication and cooling effect of cutting liquids differ in dependence on the kind of machining, materials entering into the cutting process but mainly on cutting conditions. At slower cutting speeds, relatively less heat is created, therefore in this case, the effect of decreased friction by the lubrication effect of cutting liquids prevails [5], [7].

With increasing cutting speed and relevant increase of temperature, laso cooling effect of cutting liquids increases, however, the lubrication effect by cutting liquids is disappearing. The increase of cutting tools lifetime depends not only the effective cooling for machining process but mainly at higher cutting speeds on the decrease of friction and condition for the creation of heat in this process.

The analysis of cutting process during machining according to the results of previous works confirms the use of gaseous cutting media as the reality of machining technological process [6], [8]. As well, the information from the area of tribological analysis of machining processes about the positive effect of surface oxidation during machining has been confirmed which has lead to the consideration about the use of oxidation agents in the area of cutting media.

According to the recent experience, different gaseous media $\left(\mathrm{CO}_{2}, \mathrm{~N}, \mathrm{Ar}, \mathrm{O}_{2}\right)$ have shown different effects on cutting process. The findings about the use of ozone in the area of medicine rank the element among strong oxidation agents. Air ionization is a well-known fact and considering the economical and technical availability of electrostatic obtaining of ozone it has been possible to consider the use of such produced gaseous media in the field of technology of machining.

\section{Production and application of ionized air}

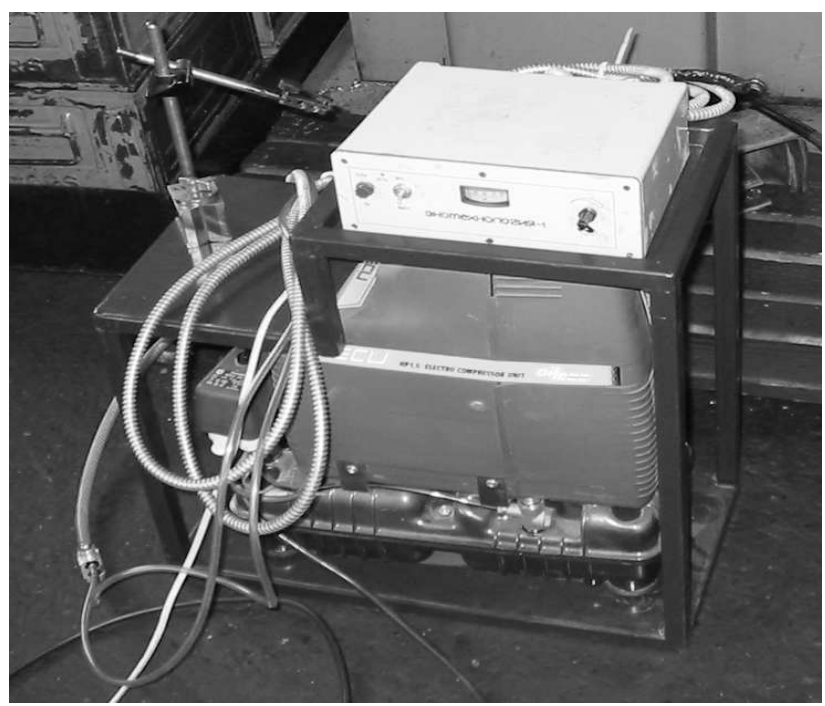

a)

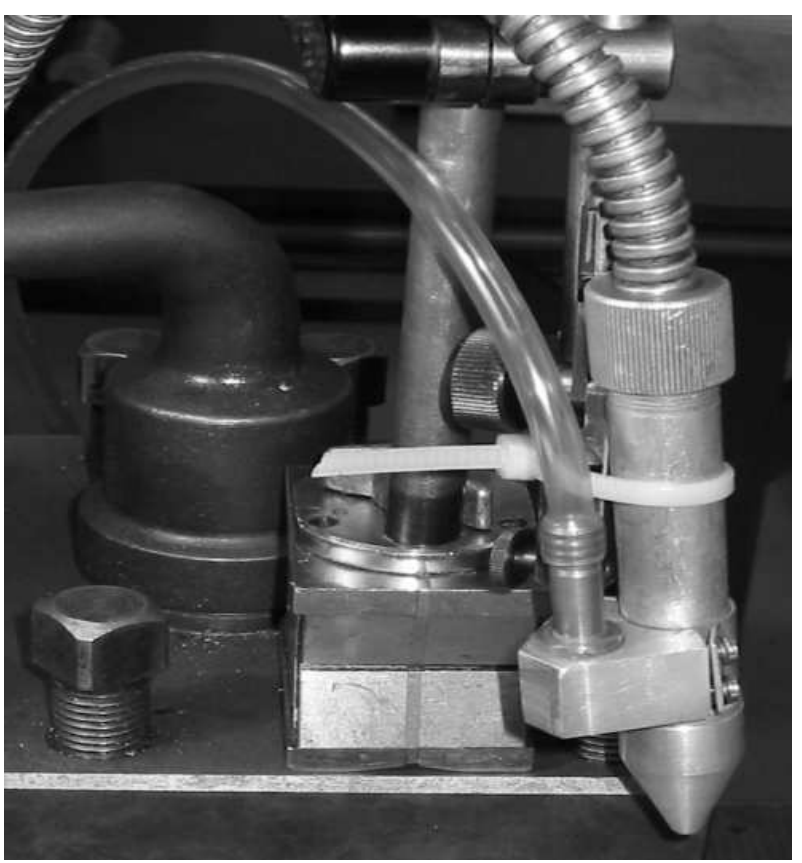

b)

Fig. 3 a) air ionizer with compressor, b) application nozzle

This part forms the essence of the application of ionized air into the cutting zone. It consists of electrostatic ionizer without oil membrane blast apparatus. An adjusted laboratory magnetic stand designated for the positioning of the application jet nozzle for ionized air is a part of the system.

Technological system consists of a centre lathe SN 55 , a ionizer and a universal air pump.

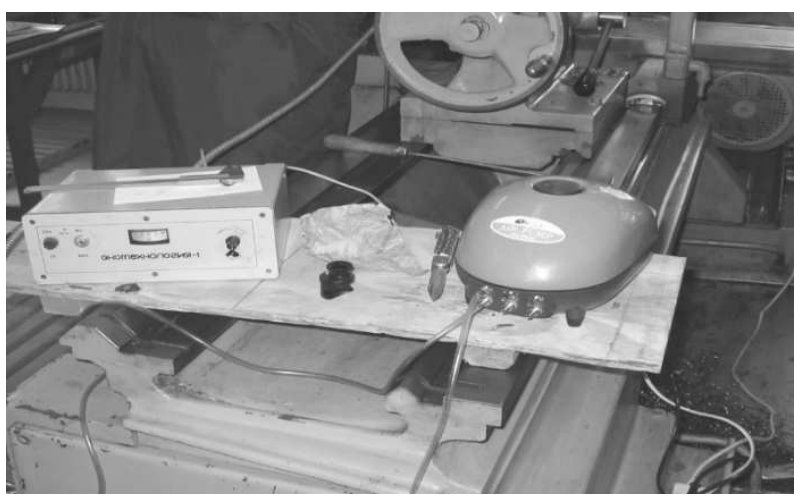

Fig. 4 Working assembly of the source o fair ionization

\section{Prezentation experimental results}

Tab. 1 Basic data

\begin{tabular}{||c|c||}
\hline \hline & $\begin{array}{c}\text { Tool : finishing knife } \\
\mathbf{2 0 x 2 0}\end{array}$ \\
\hline workpiece & rod \\
\hline $\begin{array}{c}\text { metal cutting ma- } \\
\text { chine }\end{array}$ & central lathe SN 55 \\
\hline operation & turning \\
\hline workpiece material & steel C45 \\
\hline hardness (HB) & 190 \\
\hline turning tool code & 3516 HSS 02 \\
\hline turning tool producer & B.O.S. Teplice, s.r.o. \\
\hline
\end{tabular}


The influence of ionized air on the quality of machined surface has been observed. The results are presented in Tables 2-4 and in Fig. 5.

A considerable drop in the intensity of tool wear comparable to the effects of cutting liquid can be seen.
Tab. 2 Cutting conditions

\begin{tabular}{||c|c||}
\hline cutting speed, $\mathrm{m}_{\mathrm{min}} \mathrm{m}^{-1}$ & 22.68 \\
\hline workpiece rotation frequency, $\mathrm{min}^{-1}$ & 112 \\
\hline shift, $\mathrm{mm}$ & 0.1 \\
\hline tool blunting criterion, $V B_{\mathrm{k}}, \mathrm{mm}$ & 0.3 \\
\hline
\end{tabular}

Tab. 3 Values of tool wear on the back VB depending on machining time $\tau_{s}$.

\begin{tabular}{|c|c|c|c|c|c|c|c|c|c|c|c|c|}
\hline \multirow{3}{*}{$\begin{array}{r}\begin{array}{c}\tau_{\mathrm{s}}, \\
\text { min. }\end{array} \\
5\end{array}$} & \multicolumn{6}{|c|}{ without the use of ionized air } & \multicolumn{6}{|c|}{ With the use of ionized air } \\
\hline & \multicolumn{6}{|c|}{$V B, \mathrm{~mm}$} & \multicolumn{6}{|c|}{$V B, \mathrm{~mm}$} \\
\hline & 0.09 & 0.09 & 0.08 & 0.10 & 0.09 & 0.09 & 0.04 & 0.04 & 0.04 & 0.04 & 0.04 & 0.04 \\
\hline 10 & 0.13 & 0.12 & 0.13 & 0.13 & 0.14 & 0.13 & 0.06 & 0.06 & 0.07 & 0.08 & 0.08 & 0.07 \\
\hline 15 & 0.2 & 0.1 & 0.2 & 0.2 & 0.2 & 0.2 & 0.09 & 0.08 & 0.10 & 0.10 & 0.08 & 0.09 \\
\hline 20 & 0.24 & 0.24 & 0.25 & 0.25 & 0.24 & 0.24 & 0.1 & 0.09 & 0.09 & 0.1 & 0.1 & 0.1 \\
\hline 25 & 0.3 & 0.3 & 0.3 & 0.3 & 0.29 & 0.3 & 0.11 & 0.12 & 0.12 & 0.13 & 0.11 & 0.12 \\
\hline 30 & & & & & & & 0.12 & 0.12 & 0.14 & 0.14 & 0.13 & 0.13 \\
\hline 35 & & & & & & & 0.15 & 0.15 & 0.15 & 0.13 & 0.14 & 0.15 \\
\hline 45 & & & & & & & 0.21 & 0.22 & 0.22 & 0.20 & 0.20 & 0.21 \\
\hline 50 & & & & & & & 0.24 & 0.24 & 0.25 & 0.23 & 0.24 & 0.24 \\
\hline 60 & & & & & & & 0.29 & 0.30 & 0.30 & 0.296 & 0.29 & 0.29 \\
\hline
\end{tabular}

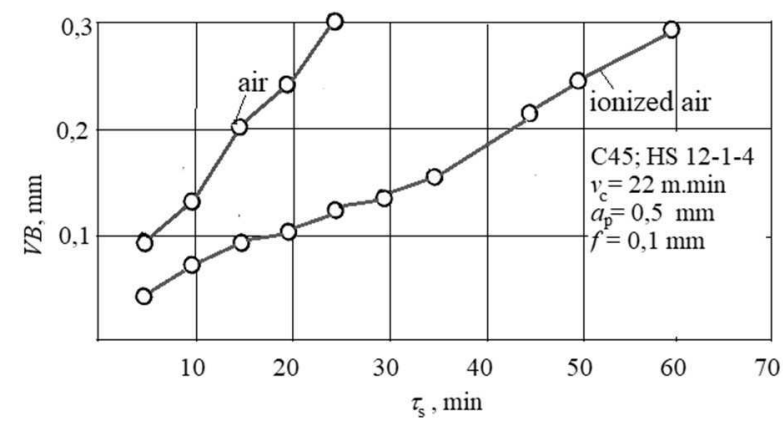

Fig. 5 Course of functional dependence of the wear VB and machining time $\tau_{s}$

\section{Evaluation of the application of ionized air}

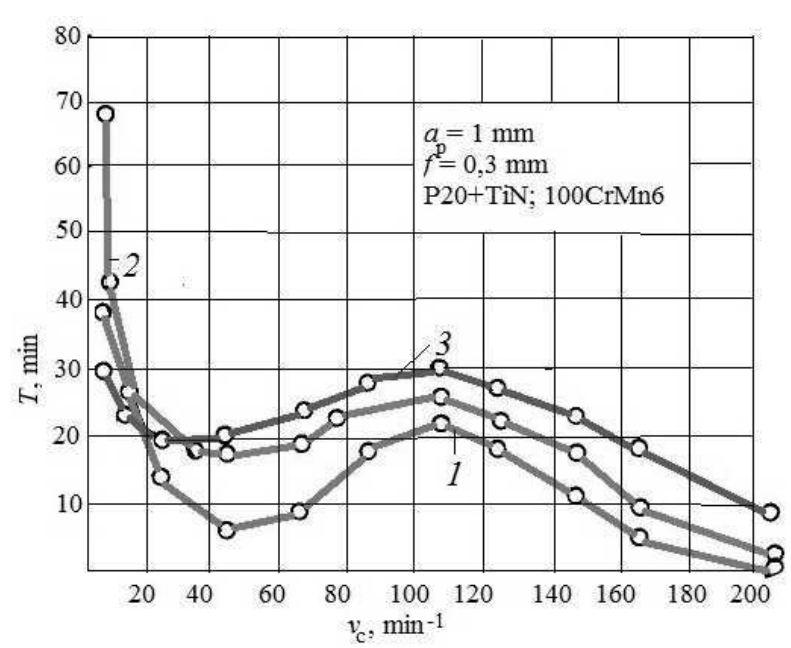

Fig. 6 Experimental dependence of tool durability on cutting speed when using gaseous and liquid environments. 1 -cooling by air, 2-emulsion, 3 -ionized air

When studying the influence of ionized air during ma- chining it has been found out that in the observed measurement interval, tool durability undoubtedly grew. This phenomenon can most likely be associated with the cooling effect of the media running through the cutting zone and chemical changes in the surface layers.

Experiments with the use of different cooling media have shown increased tool durability, mainly at higher cutting speeds. This environment has visible cooling effect and is ecologically harmless.

In Fig. 6 there is an experimental dependence of durability of the tools made of sintered carbid on cutting speed when using different cutting environments.

Generally speaking, cooling by gases is suitable for higher cutting speeds at which the cooling liquid is sprayed and does not strike the place of the contact of the tool with workpiece directly.

Besides the influence on durability, the influence of the environment on the quality of machined surface is also important. In Fig. 7 there is an experimental dependence $R z=\mathrm{f}\left(v_{\mathrm{c}}\right)$ using different environments.

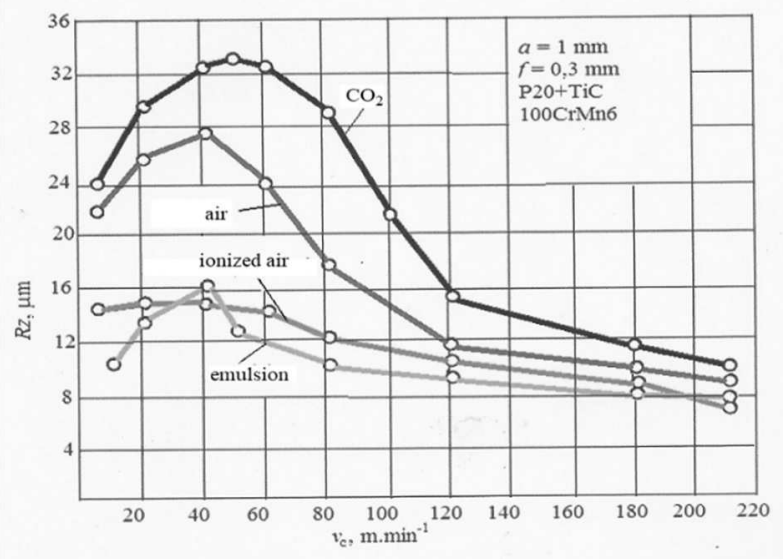

Fig. 7 Experimental dependence documenting the influence of environment on the quality of machined surface 
Liquid environment improves the quality of machined surface in whole range of the used cutting speeds. Ionized air has an effect similar to the liquid. It is more effective at higher cutting speeds (in the presented case above 200 $\mathrm{m} . \mathrm{min}^{-1}$ ), which is probably caused by higher penetrative effect into the contact of the chip and tool face (it is driven under pressure). At low cutting speeds, cutting liquid has higher effect because its dispersion does not occur.

For certain specific operations, the use of cooling by ionized air appears to be a suitable application with an important environmental effect for the working environment.

The experiments have shown that the application of ionized air by ionizer with electrostatic discharge has obtained the results equivalent with emulsion process media CIMSTAR 560.

\section{Conclusion}

The evaluation of the benefit of this interesting media has not been closed yet just with regards to the openess of the problem of use of gaseous cutting media, which would confirm the justness of the use of ionized air in the field of production technologies and cutting processes after further technological tests with this cutting environment are completed. There is a realistic option of the application of ionized air e.g. for milling of moulds for pressure casting and the production of dies for dies for drop forging as well as form milling on NC machines and machining centers, deep drilling, where the liquid permeability is limited.The secoondary effect of this cooling zone of the cutting zone is the reliable removal of the chips from the contact of the tool and the workpiece. Compared to cooling with liquid media, it does not distribute harmful waste, on the contrary, it creates a pleasant working environment (ozone).

\section{References}

[1] FRISCHHERZ, A., PIEGNER, H. (1994). Metalltechnik 2, Fachkenntnisse, Wiwn, 1994, 280 s., ISBN 0-902655-1-0

[2] AOYAMA, T. Develoment Mixture Supply System for Machining with Minimal Quantity Lubrication, Annals of the CIRP, 51/1

[3] SHIMADA, S., INAMURA, T. , HIGUCHI, M., TANAKA, H. Suppresion of Tool Wear id Diamond Turning of Copper under Reduced Oxygen Atmosphere, Annals of the CIRP, 49/1
[4] GLEEN, T., ANTWERPEN, F. (2004). Opportunities and market trend in metalworking fluids. Journal of the Society of Tribilogists and Lubrication Engineers, 4, 2004, pp. 31-34

[5] SHOKRANI, A., DHOKIA, V., NEWMAN, ST. (2012). Environmentally conscious machining of difficult-to-machine materials with regard to cutting fluids. International Journal Machine Tools Manufacturing, 2012, No.57, pp. 83-101

[6] SU, Y., GONG, I., LI, B et al. (2016). Performance evaluation of nanofluid MQL with vegetable-based oil and ester oil as base fluids in turning. International Journal Advance Manufacturing Technology, 2016, Nr. 57, pp. 2083-2089

[7] SUDA, S., WAKABAYASHI, T., INASAKI, I., YOKOTA, H. Multifunctional application of a synthetic ester to machine tool lubrication based on MQL machining lubricants. CIRP Annals, Manufacturing Technology, Nr. 3, pp. 61-64.

[8] HUANG, W-T, WU, D-H., LIN, S-P, LIU, W-S. (2016). A combinated minimum quality lubrication and MWCNT cutting fluid approach for SKD 11 end milling. International Journal Advances Manufacturing Technology, 2016, Nr. 84, pp. 1679-1704

[9] GOINDI, GS., CHAVAN, SN, MANDAL, D et al. (2014). Investigation of ionic liquids as novel metalworking fluids during minimum quantity lubrication machining of a plain carbon steel. Procedia CIRP, 2014, Nr. 26, pp. 341-345.

[10] BUMBÁLEK, B., BUMBÁLEK, L. (2002). Model of Shear Instability During Cutting. Manufacturing Technology 2002, June, pp. 37-42, 12132489

[11] HOLEŠOVSKÝ, F., HRALA, M., NOVÁK, M. (2003). Ground Surface - Quality and its Loading Capacity. Manufacturing Technology, Vol. 3, 2003, pp. 26-32, ISSN 1213-2489.

[12] JERSAK, J. et al. The Integrity of th Surface after Milling of Quenched Bearing Steel. Manufacturing Technology, No. 4, pp. 13-20, ISSN 12132489. 